\title{
PROPUESTA DIDÁCTICA PARA LA ENSEÑANZA Y APRENDIZAJE DE CONCEPTOS FÍSICOS BÁSICOS A PARTIR DEL USO DEL VIDEO DE CIENCIA FICCIÓN Y PRÁCTICAS DE AULA DEMOSTRATIVAS
}

\author{
DIDACTIC PROPOSAL FOR TEACHING AND LEARNING OF \\ BASIC PHYSICAL CONCEPTS OF THE USE OF VIDEO OF \\ SCIENCE FICTION AND DEMONSTRATION CLASSROOM \\ PRACTICES
}

\author{
Mora Moreno Maritza, Aguilar Rodríguez Favio
}

\begin{abstract}
Universidad Nacional de Colombia
Facultad de Ciencias, Maestría en Enseñanza de las Ciencias Exactas y Naturales mamoramo@unal.edu.co,maryj_aca@hotmail.com,fyaguilarr@unal.edu.co
\end{abstract}

\section{RESUMEN}

Tradicionalmente los estudiantes presentan poca apropiación de los conceptos básicos de la física, debido a que en la mayoría de casos, los conceptos se quedan en una explicación teórica y pocas veces se aplican en un contexto cotidiano. Los factores que más influyen (desde algunos estudios) en la comprensión de los conceptos están asociados directamente con las metodologías empleadas por los profesores para enseñarlos en el aula de clase, de tal manera que la propuesta que se presenta en este trabajo, tiene como objetivo contribuir a transformar los escenarios tradicionales de enseñanza y aprendizaje y para tal fin se propone aplicar la física a partir de actividades que incluyan el análisis de videos de ciencia ficción y de prácticas de aula demostrativas (dentro del marco del aprendizaje activo). La propuesta piloto se aplicó en una institución educativa del distrito, con estudiantes de grado octavo y noveno y se dirigió al estudio de conceptos básicos de electrostática y de termodinámica. Algunos de los resultados permitieron evidenciar la importancia de buscar una transformación en la enseñanzaaprendizaje, adaptando prácticas pedagógicas que fortalezcan el aprendizaje de la física al reflejarse en un aprendizaje significativo en la construcción, comprensión y consolidación de los conceptos estudiados.

PALABRAS CLAVES: Física, Didáctica, Ciencia Ficción, Aprendizaje Activo. 


\section{ABSTRACT}

Traditionally students have little ownership of the basic concepts of physics, because in most cases, the concepts remain at a theoretical explanation and rarely applied in an everyday context. The factors that most influence (several studies) in understanding the concepts are directly associated with the methodologies used by teachers to teach in the classroom, so that the proposal presented in this paper aims scenarios to help transform traditional teaching and learning and therefore propose to apply physics from activities that include video analysis of science fiction and demonstration classroom practices (within the framework of active learning). The pilot proposal was implemented in a school district with students in eighth and ninth grade and went to study basic concepts of electrostatics and thermodynamics. Some of the results showed the importance of seeking a transformation in teaching and learning, adapting teaching practices that strengthen the learning of physics to be reflected in a significant learning in the construction, understanding and consolidation of the concepts studied.

KEYWORDS: Physics, Teaching, Science Fiction, Action Learning

\section{INTRODUCCIÓN}

A pesar de las diferentes metodologías utilizadas para la enseñanza de las ciencias naturales, pareciera que la búsqueda de ese aprendizaje estuviera siendo infructuosa, pues los estudiantes no se sienten comprometidos en dicho proceso. Gran parte de la imagen que los estudiantes tienen de la ciencia y de sus ideas está basada en conceptos abstractos, debido a que en la mayoría de casos, los conceptos se quedan en una explicación teórica en el aula de clase y pocas veces se aplican en un contexto cotidiano, lo que hace que ciencias como la física se vean como una disciplina compleja, alejada de la realidad. Se propone entonces, estudiar y profundizar en los conceptos básicos de la física y aplicarlos en la comprensión y explicación de algunos fenómenos físicos a partir del análisis de videos (escenas tomadas de películas de ciencia ficción) como agentes dinamizadores de la clase y de prácticas de aula demostrativas (enmarcadas dentro del aprendizaje activo) como actividades que permitan estructurar los conceptos de los fenómenos físicos que se vieron en las escenas de los videos, lo que permitirá que el estudiante visualice y pueda imaginar, construyendo el conocimiento por medio de una narrativa propia, llevando así los conocimientos al lugar donde tienen su verdadero significado: "A la vida cotidiana".

\section{EL USO DEL VIDEO Y LA CIENCIA FICCIÓN}

Históricamente la escuela ha privilegiado la escritura casi como única forma de comunicación, de transmisión de información y de expresión; desplazando y relegando así otros lenguajes y otros canales. La incorporación del video como medio expresivo y como herramienta pedagógica en el aula introduce un nuevo lenguaje: la imagen en movimiento. De esta manera los videos pueden complementar y ampliar las formas de 
expresión en los procesos de enseñanza. El uso del video en el salón de clases facilita la construcción de un conocimiento significativo dado que se aprovecha el potencial comunicativo de las imágenes, los sonidos y las palabras para transmitir una serie de experiencias que estimulen los sentidos y los distintos estilos de aprendizaje en los estudiantes, esto permite concebir una imagen más real de un concepto.

Por otra parte, el video de ciencia ficción como género que utiliza las narraciones imaginarias (ya que no pueden darse en el mundo que se conoce) y que relata acontecimientos posibles que se fundamentan en conceptos de la ciencia, permite construir una narrativa en el estudiante ya que "La presentación de una situación científica en un contexto históricamente determinado y creíble puede impulsar la comprensión de una serie de relaciones entre el saber y las situaciones vitales como un hecho natural al ejercicio de la investigación científica. Es decir, la narración dramatizada que utiliza elementos de ficción funciona como una mímesis, en términos aristotélicos, de la situación de conocimiento y de la construcción de una imagen del mundo" (Jaramillo, 2005).

\section{LAS PRÁCTICAS DE AULA DEMOSTRATIVAS Y EL APRENDIZAJE ACTIVO}

La visualización como forma pedagógica se basa en "mostrar" mediante experimentos, símiles, demostraciones, y actividades, con el propósito de que los estudiantes construyan imágenes sobre lo mostrado, es decir, puedan imaginar construyendo sentido sobre lo que se enseña a través de conformar una narrativa propia. De alguna manera la observación atenta generará procesos de comparación y de relación lo que a su vez llevará a inferir y argumentar. Procesos como explorar, observar y comparar, relacionar e inferir y argumentar ayudan a estructurar la mente, lo cual permite construir narrativas, ordenamientos, racionalidades. El aprendizaje activo, en este sentido, es implementado como un conjunto de estrategias de aprendizaje donde los estudiantes son guiados a construir su conocimiento de los conceptos de la física, mediante la observación directa del mundo físico. El ciclo de aprendizaje incluye predicciones individuales, actividad, discusión en grupos pequeños, observación y comparación de los resultados esperados con las observaciones y finalmente la síntesis o conclusiones.

En un ambiente de aprendizaje activo los estudiantes construyen su conocimiento desde observaciones prácticas ya que permite al estudiante confrontar lo que piensa o cree saber acerca de un fenómeno físico, al comparar su predicción de un experimento (antes de realizar el experimento) con los resultados del experimento que el mismo ejecuta: Los estudiantes se vuelven consientes de las diferencias entre sus creencias (con las que vienen al salón de clases: conflicto conceptual) y las leyes que gobiernan el mundo físico, de tal forma que se presenten cambios en sus creencias al ser confrontadas con lo que observan y donde el rol del docente es guiar el proceso de aprendizaje.

\section{DESCRIPCIÓN DE LA PROPUESTA}

Preguntas de indagación, exploración o saberes previos: Se plantean una serie de preguntas que tienen que ver con el video y que pretenden explorar las ideas de los estudiantes. 
Proyección del video: selección minuciosa de las películas (se seleccionaran algunas escenas de diferentes películas) para orientar las temáticas que se pretenden analizar y profundizar desde la disciplina en un ambiente didáctico diferente a la clase tradicional, por eso lo más importante es el ¿Por qué sí o el por qué no? de los fenómenos y relaciones físicas.

Discusión sobre el video: a través de preguntas específicas que son relacionadas con la consulta previa y las preguntas generadoras que se hacen en la primera fase y las que se generen por parte de los estudiantes a partir del video. Profundizar en el componente disciplinar y dar explicaciones a los fenómenos o situaciones dudosas que se presentaron durante la proyección pero con argumentos propios de la disciplina.

Presentación de actividades demostrativas de aula: que surgen de la experiencia cotidiana que se tiene con el entorno y la facilidad de repetirse en diversos espacios por parte del estudiante, es decir actividades cuyas elementos siempre estén al alcance de los estudiantes y que puedan retomarse en la casa o en cualquier otro espacio, de tal manera que la visualización y observación sirvan en gran medida para la posible formulación conceptual de un fenómeno.

\section{UNA APLICACIÓN EN EL AULA}

Presión y densidad: La propuesta abarca primero los elementos que los estudiantes manejan de masa, fuerza, volumen, densidad, área y presión, haciendo énfasis en que para muchos estudiantes hay conceptos que significan igual, por ejemplo, fuerza es lo mismo que presión, esto radica en que el concepto, en muchas ocasiones, se había enseñado como un modelo matemático (es decir aplicación de una formula). De la misma manera la masa fue concebida en forma general como la cantidad de materia que contiene un cuerpo, un elemento, una sustancia sin tener en cuenta que en aquella noción se encuentran inmersas las características que dan origen a la materia (modelo atómico de la materia).

Aprovechando está noción, la actividad inicial que se planteó, corresponde a un modelo para demostrar que la masa esta constituida de moléculas pero que su organización en el espacio es diferente lo que implica el concepto de volumen como espacio medido en la organización espacial que tiene las moléculas que están conformando un cuerpo, con ello se pudo evidenciar que a pesar de tener una misma cantidad de moléculas, el espacio utilizado era diferente, entonces se pudo inferir por tal motivo que masa y volumen no podían ser lo mismo pero que si tienen una estrecha relación, lo que permite dar origen al concepto de densidad. De la misma forma se abordaron los conceptos de fuerza y presión a partir de sus relaciones y no de sus particularidades ya que al encontrar las relaciones en un concepto se puede de manera radical desligar las particularidades que los hacen similares con otros en sus concepciones generales. Como parte del trabajo de visualización se puso al descubierto ciertas escenas de películas de ciencia ficción que mostraran conceptos claves trabajados en clase para que los estudiantes, a partir de su conocimiento, discutieran los fenómenos físicos observados.

Conceptos físicos básicos de electrostática: El marco teórico que se debe tener en cuenta para abordar el estudio de los fenómenos electrostáticos abarca desde el concepto 
de carga eléctrica hasta la teoría elemental de campo eléctrico. Las actividades que se diseñaron y aplicaron partieron de la secuencia didáctica que se muestra en el anexo I y que resume el contenido de las actividades y sus objetivos de aprendizaje. Las prácticas de aula demostrativas (enmarcadas dentro de la metodología del aprendizaje activo) se propusieron a partir del estudio del péndulo electrostático y la secuencia del electroscopio. En cuanto al video, se abordaron escenas de las películas de ciencia ficción Matrix, Powder (Pura Energía) y el Núcleo. El video, como material didáctico argumentativo, permitió establecer una relación metafórica entre los conceptos y las secuencias a partir de un acercamiento a la realidad como una representación ajustada de un modelo de la misma, lo que fomentó la capacidad de reflexión, a través, principalmente, de la innovación, la curiosidad y el conocimiento. Las actividades fueron desarrolladas con un grupo de 40 estudiantes de educación básica secundaria (grado noveno de la I.E.D. Liceo Femenino Mercedes Nariño).

Finalmente se puede decir que la propuesta permitió mejorar los procesos de enseñanza en la comprensión de los conceptos físicos enseñados, evidenciando la importancia de hacer visible los fenómenos físicos a través de su representación, esta visibilidad es la base para la construcción de imágenes por parte de los estudiantes, lo que les permite imaginar, es decir, ir construyendo sentido y significado y una conceptualización más racionalizadora que es expresada a través de una narrativa. Es importante resaltar que los símiles se pueden utilizar de diversas maneras y son de gran ayuda para visualizar fenómenos y conceptos, cuando se utilizan junto con otras actividades (demostraciones, experimentos) y sirven para construir una "morfología del fenómeno o concepto".

\section{REFERENCIAS}

García, J. (2008). Bienvenido Míster cine a la enseñanza de las ciencias. Revista Eureka: Enseñanza divulgación y ciencia. 6 (1), 79-91.

Guisasola, J. (1999). Enseñanza aprendizaje de la teoría eléctrica que explica los fenómenos electrostático básicos. Alambique didáctica de las ciencias experimentales. № 19, 9-18.

Jaramillo, A. (2005). Vídeo argumental y educación en ciencias: una relación paradójica. Comunicar. Revista Científica de Comunicación y Educación. 24, 121-128.

Magendzo, A. (2006). Recontextualización Curricular: Campo de recontextualización oficial y campo de recontextualización pedagógica.

Palacios, S. (2007). El cine y la literatura de ciencia ficción como herramienta didáctica en la enseñanza de la física: una experiencia en el aula. Revista Eureka: enseñanza, divulgación y ciencia. 4 (1), 106-122.

Schwartz, S y Pollishuke, M. Aprendizaje activo: Una organización en la clase centrada en el alumno. Madrid, España. Narcea ediciones.

Torres, A. (2010). The experimental and historical foundations of electricity. Montréal, Canada. Library and Archives Canada Cataloguing in Publication. 


\section{ANEXO I \\ SECUENCIA DIDÁCTICA}

\begin{tabular}{|c|c|c|c|}
\hline $\begin{array}{l}\text { Contenido } \\
\text { abordado }\end{array}$ & $\begin{array}{l}\text { No de } \\
\text { sesione } \\
\text { s }\end{array}$ & $\begin{array}{l}\text { Contenidos de las } \\
\text { actividades }\end{array}$ & Objetivos de aprendizaje \\
\hline $\begin{array}{l}\text { 1. Fenómenos } \\
\text { eléctricos: } \\
\text { Mediante el cine } \\
\text { de ciencia } \\
\text { ficción. }\end{array}$ & 1 & $\begin{array}{l}\text { A.1: Motivación hacia } \\
\text { el estudio del tema: } \\
\text { Proyección del video, } \\
\text { preguntas orientadoras } \\
\text { y discusión. } \\
\text { Actividad de consulta. } \\
\text { Escenas tomadas de } \\
\text { las siguientes } \\
\text { películas: Matrix, } \\
\text { Powder y el Núcleo. } \\
\text { (Duración del video } 28 \\
\text { minutos) }\end{array}$ & $\begin{array}{l}1.1 \text { Reconocer la presencia de } \\
\text { fenómenos eléctricos en la vida } \\
\text { cotidiana (Relación Ciencia, Tecnología } \\
\text { y Sociedad). } \\
1.2 \text { Despertar la curiosidad y/o el } \\
\text { interés por el estudio de algunos } \\
\text { fenómenos eléctricos presentes en la } \\
\text { naturaleza. }\end{array}$ \\
\hline $\begin{array}{l}\text { 2. Conceptos } \\
\text { físicos (básicos) } \\
\text { de } \\
\text { electrostática: } \\
\text { Estructura de la } \\
\text { materia }\end{array}$ & 1 & $\begin{array}{ll}\text { A.2: } & \text { Actividad } \\
\text { experimental } & \\
\text { demostrativa, } & \\
\text { preguntas } & \\
\text { orientadoras. } & \text { Prueba } \\
\text { de entrada. } & \\
& \end{array}$ & $\begin{array}{l}2.1 \text { Construir en la estudiante un } \\
\text { conocimiento "provisional" sobre } \\
\text { conceptos físicos básicos referentes al } \\
\text { estudio de la electrostática. }\end{array}$ \\
\hline $\begin{array}{l}\text { 3. Fenómenos } \\
\text { eléctricos: el } \\
\text { video en la } \\
\text { enseñanza de la } \\
\text { física. } \\
4 . \text { Construcción } \\
\text { de conceptos: } \\
\text { Naturaleza } \\
\text { eléctrica de la } \\
\text { materia ¿ un } \\
\text { ¿Cuándo está } \\
\text { cuerpo } \\
\text { cargado } \\
\text { eléctricamente? }\end{array}$ & 1 & $\begin{array}{l}\text { A.3: Proyección del } \\
\text { video, preguntas } \\
\text { orientadoras y } \\
\text { discusión. } \\
\text { (Video sobre la historia } \\
\text { de la electricidad } \\
\text { contado en dibujos } \\
\text { animados, duración del } \\
\text { video } 5 \text { minutos) } \\
\text { A.4: Revisión de la } \\
\text { estructura del átomo y } \\
\text { determinación del } \\
\text { estado eléctrico de los } \\
\text { materiales a partir del } \\
\text { concepto de carga } \\
\text { neta. }\end{array}$ & $\begin{array}{l}\text { 3.1 Utilizar el video, como material } \\
\text { didáctico argumentativo, para iniciar el } \\
\text { estudio del tema a partir del desarrollo } \\
\text { histórico y epistemológico de las ideas } \\
\text { sobre los fenómenos eléctricos. } \\
4.1 \text { Poner de manifiesto la naturaleza } \\
\text { eléctrica de la materia. } \\
4.2 \text { Entender que los átomos son } \\
\text { eléctricamente neutros porque tienen el } \\
\text { mismo número de electrones y } \\
\text { protones. } \\
4.3 \text { Entender que el estado eléctrico de } \\
\text { un material viene determinado por un } \\
\text { equilibrio entre el número de electrones } \\
\text { y protones. }\end{array}$ \\
\hline $\begin{array}{l}\text { 5. Electrización: } \\
\text { ¿Cómorr se } \\
\text { electrizan los } \\
\text { cuerpos? }\end{array}$ & 1 & $\begin{array}{lr}\text { A.5: Realización de } \\
\text { experiencias sencillas } \\
\text { de electrización, } \\
\text { analizando r } \\
\text { discutiendo ry } \\
\text { fenómenos } \\
\text { observados. }\end{array}$ & $\begin{array}{l}\text { 5.1 Comprender que la electrización de } \\
\text { un material se debe, exclusivamente, a } \\
\text { la pérdida o ganancia de electrones. } \\
5.2 \text { Comprender que la separación de } \\
\text { cargas en la electrización por inducción, } \\
\text { se debe al movimiento de electrones } \\
\text { por la acción de una carga externa. } \\
5.3 \text { Entender que el movimiento de los } \\
\text { electrones en los materiales depende } \\
\text { de la estructura atómica de estos. }\end{array}$ \\
\hline
\end{tabular}




\begin{tabular}{|c|c|c|c|}
\hline 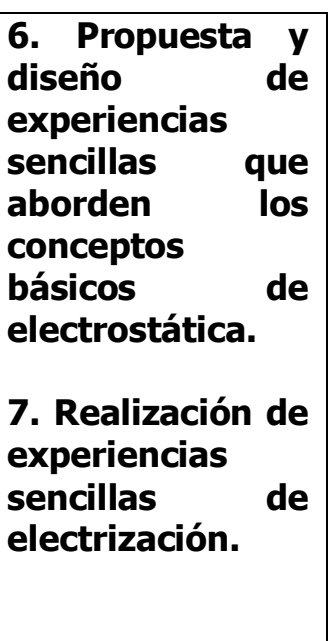 & 2 & $\begin{array}{l}\text { A.7: Realización de las } \\
\text { prácticas } \\
\text { experimentales. } \\
\text { Discusión y análisis de } \\
\text { los fenómenos (trabajo } \\
\text { en grupo). }\end{array}$ & $\begin{array}{l}6.1 \text { Construcción por parte de la } \\
\text { estudiante del conocimiento necesario } \\
\text { sobre conceptos físicos básicos para } \\
\text { explicar los fenómenos referentes al } \\
\text { estudio de la electrostática. }\end{array}$ \\
\hline $\begin{array}{l}\text { 8. Construcción } \\
\text { de conceptos: } \\
\text { Interacción } \\
\text { entre cargas } \\
\text { eléctricas en } \\
\text { reposo (Ley de } \\
\text { Coulomb, campo } \\
\text { eléctrico) }\end{array}$ & 1 & $\begin{array}{l}\text { A.8: Estudio del } \\
\text { modelo de acción a } \\
\text { distancia (Newton) y } \\
\text { del modelo de campo. }\end{array}$ & $\begin{array}{l}\text { 8.1 Comprender las limitaciones del } \\
\text { modelo de Coulomb (acción a distancia) } \\
\text { para interpretar las interacciones } \\
\text { eléctricas. } \\
8.2 \text { Comprender el papel que juega el } \\
\text { campo eléctrico como nueva } \\
\text { interpretación de la interacción } \\
\text { eléctrica. }\end{array}$ \\
\hline $\begin{array}{l}\text { 9. Conceptos } \\
\text { físicos (básicos) } \\
\text { de electrostática }\end{array}$ & 1 & $\begin{array}{l}\text { A.9: Actividad } \\
\text { experimental } \\
\text { demostrativa, } \\
\text { discusión preguntas } \\
\text { orientadoras. Repetir } \\
\text { la prueba de entrada. }\end{array}$ & $\begin{array}{l}\text { 9.1 Evidenciar en la estudiante el } \\
\text { avance en su conocimiento y } \\
\text { comprensión sobre conceptos físicos } \\
\text { básicos referentes al estudio de la } \\
\text { electrostática. } \\
\text { 9.2. Compara las ideas iniciales de las } \\
\text { estudiantes con las ideas que han } \\
\text { construidos después del estudio del } \\
\text { tema. }\end{array}$ \\
\hline $\begin{array}{l}10 . \text { Fenómenos } \\
\text { eléctricos: el } \\
\text { cine de ciencia } \\
\text { ficción en la } \\
\text { enseñanza de la } \\
\text { física. }\end{array}$ & 1 & $\begin{array}{l}\text { A.10: Repetir la } \\
\text { proyección del video, } \\
\text { las preguntas } \\
\text { orientadoras y realizar } \\
\text { la discusión. } \\
\text { Conclusiones y } \\
\text { observaciones finales. }\end{array}$ & $\begin{array}{l}\text { 10.1 Confrontar las ideas iniciales de las } \\
\text { estudiantes y describir sus avances en } \\
\text { la comprensión, explicación y } \\
\text { aprendizaje de los conceptos físicos } \\
\text { básicos referentes al estudio de la } \\
\text { electrostática. }\end{array}$ \\
\hline
\end{tabular}

